\title{
UM CARNAVAL FORA DA LISTA QUANDO A IDENTIDADE É CRIADA PARA 0 MERCADO
}

\author{
Edson Leite \\ Maria Cristina Caponero \\ Simone Perez
}

Este artigo busca compreender como a dinâmica de mercado interfere na prática do carnaval do Rio de Janeiro (Brasil), um dos mais conhecidos no mundo, que fica fora da Lista de obras-primas do patrimônio oral e imaterial da humanidade, da Unesco, diferente do carnaval de Oruro (Bolívia), de Barranquilla e de Negros e Brancos (ambos na Colômbia). [abstract on page 278]

\section{CARNAVAL, PATRIMÔNIO IMATERIAL, FESTAS POPULARES.}

LEITE, Edson, CAPONERO, Maria Cristina, PEREZ, Simone. Um carnaval fora da lista: quando a identidade é criada para o mercado. Textos escolhidos de cultura e arte populares, Rio de Janeiro, v.7, n.2, p. 97 108, nov. 2010. 


\section{FESTA, CONSTRUÇÃO DE IDENTIDADE E CULTURA NACIONAL}

Não existe sociedade humana sem festas, sejam elas seculares, tradicionais ou modernas. Segundo Lanternari (apud FERREIRA, 2001), as festas populares contribuem para a construção da identidade e da cultura nacionais, sendo elemento marcante e constitutivo da vida, além de expressões vivas e dinâmicas da cultura popular. Por meio das festas se expressa o modo de vida dos povos e suas tradições, abrangendo todas as classes sociais, pois onde há alguma vida popular articulada há sempre uma cultura tradicional, material e simbólica com consciência de sua identidade.

A festa pode ser entendida como elemento constitutivo do modo de vida especificamente popular de uma nação, consistindo num conjunto de cerimônias, de rituais coletivos, pois na festa há sempre algum motivo de agregação dos participantes, que reafirmam laços sociais e aproximam os homens, traduzindo a cultura popular, a linguagem do povo e sua própria identidade.

Trata-se, portanto, de eventos de grande poder aglutinador, marcando as comunidades e seus praticantes, sendo elo identitário de pessoas e de grupos, pois permitem criar culturas, símbolos e identidades, tornando necessários, em alguns casos, esforços coletivos de preservação. Elas estariam dentro de um quadro coletivo da memória, pois produzem e reproduzem a história e a memória, uma vez que todos os povos têm uma história, marcada por eventos distintos e refletida nas festas populares, demonstrando que a agregação dos participantes não só pode gerar sentimento de identidade entre eles, como também pode ser influenciada e registrada tanto na memória individual quanto na coletiva. Em outras palavras, "qualquer que seja a relação da memória individual com a memória coletiva, é no âmago da primeira que se realiza de fato, a segunda" (MUKUNA, 2006, p. 59).

Resgatando lembranças e emoções, as festas recriam algo que ficou na memória coletiva, sendo instrumentos valiosos de guarda dessa memória, pois não basta reconstruir pedaço a pedaço a imagem de um acontecimento passado, é preciso que essa reconstrução funcione a partir de dados e noções comuns que estejam em nosso espírito e também no dos outros.

As festas são sempre as mesmas, sem nunca ser iguais, pois são resultantes do aprendizado que se dá pela interação social. Possuem dinâmica própria, transformandose, atualizando-se, de forma lenta, fora do ritmo acelerado das expressões massivas, embora apresentem uma relação entre tradição e inovação, o que constitui forte dinamismo, elemento de vitalidade da festa. Sob esse ponto de vista, pode-se afirmar que uma festa popular não é uma reprodução intacta de rituais passados; ela se mantém pela tradicionalidade e não pela sobrevivência do passado pois "a festa se apresenta como mediação entre o passado e o futuro, realizada no presente e através da qual a humanidade poderia caminhar no tempo, tanto para frente quanto para trás" (ELIADE, 2002, p.55). As festas populares podem ser entendidas como "um conjunto de práticas, normalmente reguladas por regras tácitas ou abertamente aceitas, tais práticas de natureza ritual ou 
simbólica, visam inculcar certos valores e normas de comportamento através da repetição, o que implica automaticamente uma continuidade em relação ao passado" (HOBSBAWM, 1997, p. 9).

Dessa forma, pode-se afirmar que as festas são a somatória de contribuições de diversas gerações que as mantém vivas e reavivadas na memória popular e consequentemente na memória coletiva das pessoas do local onde se realizam.

\section{LISTA DE OBRAS-PRIMAS DO PATRIMÔNIO ORAL E IMATERIAL DA HUMANIDADE}

Desde a Segunda Guerra Mundial nota-se uma ampliação do movimento internacional de salvaguarda do patrimônio material e, mais recentemente, do imaterial, no qual estão inseridas as festas populares por sua importância sociológica, política, psicossocial e histórica na formação do caráter identitário de uma nação. Em praticamente todos os países existem diversas festas centenárias, mas apenas algumas estão inscritas na Lista de obras-primas do patrimônio oral e imaterial da humanidade da Organização das Nações Unidas para a Educação, a Ciência e a Cultura - Unesco.

Se pensarmos na América Latina, especificamente nos países latino-americanos membros do Centro Regional para la Salvaguardia del Patrimonio Cultural Inmaterial de America Latina - Crespial, chama a atenção o fato de existirem nessa região milhares de festas populares, sobretudo religiosas, em homenagem aos santos em geral, ou mesmo profanas, e muitas delas estarem inscritas na lista da Unesco, com destaque para a Colômbia, que apresenta maior representatividade, com três festas consideradas simultaneamente Patrimônio da Nação e inscritas na Lista: a Procissão de uma Semana em Popayán (2009), o Carnaval de Barranquilla (2003) e o Carnaval de Negros e Blancos (2009). Também a Bolívia se destaca pela inscrição do Carnaval de Oruro (2001).

As festas de carnaval que ocorrem na América Latina se destacam, pois ajudaram a construir a memória e a identidade dos povos latino-americanos e, ao longo das décadas, conseguiram se manter frente à lógica do mercado globalizado. São festas representativas em seus países e até mesmo fora deles, sua importância não se limitando ao fato de estarem inscritas na Lista de obras-primas do patrimônio oral e imaterial da humanidade, da Unesco, como é o caso das festas de carnaval citadas, do Carnaval de Santa Marta, na Colômbia, considerado patrimônio apenas da cidade, do Carnaval do Rio de Janeiro, no Brasil, que não consta em nenhuma lista do patrimônio, seja mundial, federal, estadual ou mesmo municipal, além de diversas outras festas de carnaval que ocorrem em várias localidades do mundo e que não foram destacadas neste texto.

Cabe lembrar que o Brasil tem legislação específica para o patrimônio imaterial e, no nível federal, duas festas registradas como Patrimônio Imaterial pelo Instituto de Patrimônio Histórico e Artístico Nacional - Iphan: o Círio de Nossa Senhora de Nazaré em Belém (PA) e a Festa do Divino Espírito Santo em Pirenópolis (GO). A grandiosidade dessas festas atrai anualmente milhares de pessoas, participantes ou meros espectadores, e assim as transforma em um dos principais produtos da região em que estão inseridas, 
movimentando a economia local na recepção de fluxos turísticos pelos hotéis e restaurantes da cidade e demais serviços de infraestrutura. Essas festas se tornaram espetáculos capazes de atrair multidões.

Por que o Carnaval do Rio de Janeiro não é reconhecido como patrimônio nacional como o Círio e a Festa do Divino e não está inscrito na Lista de obras-primas do patrimônio oral e imaterial da humanidade da Unesco, tal como o Carnaval de Oruro (Bolívia), o de Barranquilla e o de Negros e Brancos (ambos na Colômbia)? O Carnaval do Rio não está enquadrado no conceito de formação de capital simbólico?

\section{O CARNAVAL DE ORURO, OU LLAMERADA, NA BOLÍVIA}

O Carnaval de Oruro, ou Llamerada, foi inscrito na Lista em 2001. A festa existe desde o século XVII. Em 1606 o lugar foi tomado pelos espanhóis, que a proibiram, mas a festa persistiu sob as aparências da liturgia cristã, fazendo com que os deuses locais adotassem a fisionomia dos ícones cristãos, transformando-se em santos católicos.

É a maior e mais significativa festa popular boliviana e o único carnaval no mundo que tem sentido religioso; em devoção à Virgem del Socavón, constitui magnífica demonstração do sincretismo religioso-pagão, manifestação da cultura e expressões folclóricas, atraindo a participação de pessoas de todas as idades sem distinção de classes sociais ou políticas.

O Carnaval de Oruro ocorre uma vez por ano e dura dez dias, ao longo dos quais há o desdobramento de diversas artes populares. Durante a festa ocorrem inúmeros desfiles e danças típicas. Vários grupos folclóricos apresentam coreografias dedicadas inteiramente à Virgem. Há forte culto ao diabo, representado em fantasias com chifres e em máscaras horrendas utilizadas nas danças dos diabos ou diabladas, que simbolizam a luta do bem contra o mal. Na coreografia, os diabos avançam em colunas correspondendo aos sete pecados capitais. É uma verdadeira encenação teatral em que os dançarinos representam a luta entre os seres do inferno, o mal e as fúrias.

Também há fantasias que simbolizam o culto andino, na pessoa de bruxos e feiticeiros. Os mitos locais, como o sapo, a víbora, o condor, o lagarto e as formigas também estão presentes para a realização da challa como agradecimento à pátria mãe.

Outras danças de grande significado que se fazem presentes são, entre outras, morenada, tobas, caporales, waca-waca, tinku, suri sicuri, algumas originárias da tradição cultural afro da Bolívia.

\section{O CARNAVAL DE NEGROS E BRANCOS, NA COLÔMBIA}

O Carnaval de Negros e Brancos (El Carnaval de Negros y Blancos), realizado desde 1928 em San Juan del Pasto, cidade andina no sudoeste da Colômbia, é considerado Patrimônio Cultural da Nação desde 2002, além de estar inscrito na Lista desde 2009. Surgido das tradições nativas andinas e hispânicas, o Carnaval de Negros e Brancos atrai pessoas de todas as classes sociais, fazendo com que participem ativamente, seja como 
protagonistas principais ou secundários, cada um desempenhando um papel para tornar esse carnaval não apenas uma manifestação popular regional, mas do mundo todo.

Em seu primeiro dia, celebra o Carnaval da Água, quando se borrifa água nas ruas e casas para criar uma atmosfera lúdica. Em 31 de dezembro ocorre o Desfile do Ano VeIho, do qual as pessoas participam carregando pelas ruas bonecos satíricos representando personalidade ou eventos atuais. Essa jornada é finalizada com um ritual de cremação do ano velho. Os dois últimos dias de Carnaval são os mais importantes, quando todos os participantes independentemente da raça se maquiam de negros no penúltimo dia, pintando os rostos e braços uns dos outros até que todos fiquem pintados de negro para se "sentir afro-colombianos por um dia", como dizem. No último dia, jogam talco uns nos outros para todos se tornarem brancos, simbolizando assim a igualdade e unindo todas as pessoas sem distinção étnica ou cultural.

Durante o Carnaval de Negros e Brancos todos os turistas nacionais e estrangeiros podem apreciar o talento e a criatividade dos artesãos, em festa que tem como componentes as fantasias individuais e dos grupos, as bandas dos músicos ambulantes e os carros alegóricos, fazendo desse evento um período de convivência intensa, no qual tudo se converte em apresentação das artes carnavalescas envoltas em muita alegria, serpentina e talco ao som das orquestras locais e estrangeiras.

\section{O CARNAVAL DE BARRANQUILLA, NA COLÔMBIA}

O Carnaval de Barranquilla, cidade colombiana com maior diversidade cultural e comercial, ocorre desde o século XIX. Durante os quatro dias que antecedem a Quaresma Barranquilla fica repleta de cores e muita diversão, atraindo milhões de pessoas da cidade, da região, do próprio país e até estrangeiras, gerando comércio informal e pequena indústria que trabalha o ano todo para suprir a demanda de insumos para o carnaval que ocorre nesse espaço cultural.

O Carnaval de Barranquilla é conhecido por ser uma das expressões mais autênticas do povo colombiano e um dos mais populares do mundo. Não se trata de uma transplantação de fantasias, danças e músicas, mas de um espaço de reivindicação de liberdade e convivência como alternativa para a construção do tecido social e a criação simbólica, através da festa, como forma de evocar e também de caricaturizar a dor.

É manifestação cultural resultante da tríplice fusão cultural: europeia, africana e indígena, na qual as festividades católicas trazidas pelos espanhóis se misturaram aos cerimoniais aborígenes e à herança musical dos escravos africanos, como forma de resistência dos povos que perderam seus mitos, crenças e expressões culturais frente a uma cultura dominante, no caso espanhola.

Barranquilla sempre fez de seu carnaval mais do que manifestação cultural - suas danças e músicas contribuíram para a formação da identidade colombiana. O carnaval está imerso na vida das pessoas não apenas em sua participação, mas também na execução das danças, na elaboração das máscaras, na execução das roupas e outras ativida- 
des que duram vários meses e que envolvem todo o núcleo familiar, detentor da tradição. Mesmo sofrendo a influência do mundo globalizado e a penetração de uma cultura homogeneizadora imposta pelos países do primeiro mundo, o Carnaval de Barranquilla tornou-se uma das tradições mais conhecidas na Colômbia, ao lado do Carnaval de Negros e Brancos.

Por estar situada entre duas cidades, Santa Marta e Cartagena, e por se formar com a imigração, Barranquilla constituiu um tecido social e cultural muito diversificado o que fez com que o carnaval se tornasse símbolo de coesão social. O Carnaval de Santa Marta "é um dos signos vitais da cidade e uma das reconhecidas fontes do Carnaval de Barranquilla" (SINNING, 2009, p. 31), além de ser muito importante para os colombianos dentro de sua lógica socioeconômica e cultural, embora não tenha reconhecimento equivalente ao do carnaval barriquenho. Sua realização é de vital importância para os habitantes da região, e todos os cidadãos têm a obrigação de contribuir para que o carnaval seja uma verdadeira festa popular coletiva. A cidade se paralisa produtivamente e é declarado feriado cívico para garantir a participação geral da população nessa festa considerada "a mais alegre do mundo" segundo Sinning (2009, p. 46), além de ser patrimônio da cidade.

\section{NO BLOCO DOS EXCLUÍDOS: O CARNAVAL DO RIO DE JANEIRO}

Objetivando entendimento mais amplo da não inclusão do carnaval do Rio de Janeiro na Lista de obras-primas do patrimônio oral e imaterial da humanidade, da Unesco e do fato de nem mesmo ter sido registrado como Patrimônio Imaterial Brasileiro pelo Iphan, procurou-se compreender a historiografia dessa festa tão conhecida internacionalmente.

Queiroz (2005) explica que havia, até o início do século XX, distinção entre o carnaval que designava exclusivamente as brincadeiras da elite e o "pequeno carnaval", "não carnaval" ou "entrudo", das camadas populares, evidenciando as tensões e diálogos socioculturais que permeavam o palco carnavalesco.

Após a Revolução de 1930, o Estado tentou, dentro da proposta de integração nacional, criar as bases de uma ideologia que, mesmo considerando a heterogeneidade cultural brasileira, fosse genuinamente nacional. Segundo Ortiz, "os intelectuais têm neste processo um papel relevante, pois são eles os artífices deste jogo de construção simbólica" (1994, p. 142). Outra circunstância que ajudou a construção do significado do carnaval como expressão da brasilidade e da tradição do povo foi o movimento modernista que se formou no país após a Semana de Arte de 1922, realizada no Teatro Municipal de São Paulo. Nesse período, a elite brasileira composta por escritores, artistas, políticos, intelectuais e jornalistas, entre outros, buscou valorizar o que fosse "genuinamente nacional", e o carnaval não era exceção. Após a década de 1920 formou-se no Brasil duas correntes antagônicas de pensamento nacionalista: uma desejava um Brasil mais civilizado, porém dentro de um modelo europeu; a outra seguia no rumo contrário e buscava valo- 
rizar "as manifestações carnavalescas mais ligadas à cultura do interior do país, que expressassem a essência da alma brasileira" (FERREIRA, 2004, p. 250).

Já em âmbito internacional outros fatores contribuíram para que o carnaval passasse a ser visto dentro e fora do Brasil como um produto brasileiro. Segundo Ferreira (2004), um desses fatores foi a valorização da cultura negra que surgiu na Europa no início do século XX conhecida, principalmente na França, como "negrofilia", que constituiu um dos elementos que a vanguarda parisiense alastrou e que ajudou a disseminar no mundo a visão do carnaval brasileiro.

Segundo Nogueira (2008), o processo de organização da nova festa carnavalesca, pautada na junção de interesses das manifestações do Grande e do Pequeno Carnaval, representados por elite e povo, respectivamente, dar-se-ia a partir do século XX com a imposição gradativa de regulamentações cada vez mais estruturadas por parte do poder público como, por exemplo, policiamento ostensivo nos locais da festa, definição prévia do itinerário dos grupos carnavalescos e roteirização dos logradouros. O novo carnaval vai-se estabelecendo, desse modo, não como simples imposição da civilidade contra a barbárie ou como uma reação dos grupos populares a uma espécie de assalto às elites, mas sim como uma festa negociada entre ambas as partes, dominada pelas elites, que também expressavam gostos populares. Dessa forma, a relação desse conjunto de interesses com outros elementos que contribuíram nesse processo de elaboração do carnaval como fato social brasileiro, e com estas manifestações populares antes vistas com preconceito, passou a ser detentora do espírito da nação, fruto do amálgama e da hibridação cultural de nosso país. Esse projeto de criação de um espírito de grupo foi bastante encampado pelo Estado brasileiro. Tomando-se como referência conjectural a constituição do Estado Novo e posteriormente o golpe de 64, percebemos que a relação entre a cultura popular e o poder público se estabelece a partir da expansão de uma rede de instituições culturais, pela criação de cursos de ensino superior e através da elaboração de uma ideologia da cultura brasileira (ORTIZ, 1994).

A cultura, entremeando esses dois momentos, passou a ser a base para a integração nacional, dentro de perspectiva autoritária que atendesse a objetivos nacionais específicos na noção de comunidade nacional. Nesse momento histórico a fórmula ideológica do Estado girava em torno da unidade nacional: o Brasil como país mestiço. A temática, tratada desde o final do século XIX, ganhou novas abordagens, já equacionadas até os anos 30, pela ideia de país formado pela fusão de três etnias (brancos, negros e índios) e

o Estado, assume o argumento da unidade na diversidade, tornando-se brasileiro e nacional e ocupando uma função neutra de salvaguarda da identidade definida pela história. O carnaval adquire, neste cenário, um papel sintetizador de identidades e símbolos. (...) Através da dramatização inerente nos rituais, estas podem ser transformadas em instrumentos capazes de individualizar a coletividade como um todo, dando-Ihe identidade e singularidade. Elemento, portanto, representativo da alma social brasileira, baseada na relação harmônica da miscigenação étnica e da diversidade cultural que compõem o país (NOGUEIRA, 2008, p. 52). 
Quem também ajuda a desmitificar a ideia de originalidade cultural do ser brasileiro é Pierucci ao afirmar que alguns componentes integrantes do repertório de brasilidade são muito mais recentes e atuais do que podemos imaginar. Isso derruba a concepção de historicidade inserida no carnaval carioca. Ele nega a antiguidade dos traços culturais, ou seja, a vontade de identidade nacional transforma o recente no antigo, a novidade em tradição, dessa forma:

os elementos que ajudam a formar a nossa identidade teriam sido forjados de maneira proposital, possivelmente pelo Estado (...) para criar inconscientemente uma identidade nacional que remonta a um passado mais antigo do que é de fato. Assim, fenômenos sociais, muitas vezes, revestidos pela aura de memória nacional, que se incorporam em nossa consciência identitária como símbolos de brasilidade são calcados por elementos contemporâneos, bem mais recentes que o mito de origem. Estes elementos, tidos como símbolos de brasilidade, foram rapidamente absorvidos, na sociedade de consumo, pelo Turismo. Já em fins dos anos de 1920, o Rio de Janeiro começava a se projetar como polo turístico internacional. Neste momento, o carnaval carioca, além da beleza natural da cidade, começava a se configurar como um atrativo capaz de fazer com que o visitante passasse uma temporada maior (PIERUCCI, apud NOGUEIRA, 2008, p. 2).

Nogueira (2008) cita dois jornais: um do final da década de 1920 e outro do início da década de 1930, que mostram o empenho do prefeito do Rio de Janeiro em tornar o carnaval uma festa oficial da cidade e cada vez mais conhecida no país e no mundo. $O$ artigo O carnaval e o turismo, do jornalista Nóbrega da Cunha, escrito para O Jornal de 10 de fevereiro de 1929, explica o seguinte:

esses turistas estavam aqui não por causa dos bailes de máscaras, do corso ou da decoração da cidade, elementos comuns nas festas carnavalescas do exterior, mas sim para ver o carnaval "tipicamente brasileiro" (...) o grande objetivo por trás de todo esse investimento em dinheiro e em organização era a obtenção de divisas provenientes de um produto cada vez mais valorizado em escala mundial: uma festa "popular" como não existia outra no mundo (NOGUEIRA, 2008, p. 54).

Já a segunda matéria, publicada no Diário de Notícias de 4 de fevereiro de 1932, escrita por Berilo Neves, afirma que a oficialização da festa não significava a perda da espontaneidade ou da alma da festa, já então simbolizada pela miscigenação das três etnias que compunham a identidade nacional. Essa natureza, tal como abordada no texto, era o que diferenciava a folia brasileira das outras festas carnavalescas importantes.

Nos dois textos se evidencia a tentativa de valorizar argumentos históricos para obtenção da grande vantagem econômica que a festa poderia trazer para o país, principalmente no período em que o carnaval ganhou força, época em que se buscava organizar a economia dentro dos novos parâmetros da industrialização. Nogueira afirma que gerar divisas e atrair dólares e libras (nessa época o euro ainda não existia) era o argumento final e avassalador que justificaria todo o investimento da festa carioca.

O carnaval do Rio de Janeiro emprega, atualmente, sete mil pessoas, calculando-se que cada uma das 14 escolas de samba do Grupo Especial deve contratar em mé- 
dia 500 profissionais entre setembro e fevereiro. ${ }^{1}$ Estima-se que essa festa movimente cerca de um bilhão de reais em negócios e gere mais de 300 mil postos de trabalho por ano, o que dá uma ideia do poder dessa indústria. Estão excluídas desses cálculos as 58 escolas de samba dos grupos de acesso e as empresas que fornecem serviços ou produtos para os carnavalescos. Uma escola de samba pequena, como a Acadêmicos da Rocinha, por exemplo, trabalha com investimento calculado entre cinco e sete milhões de reais para brigar pelo título.

Atualmente o carnaval do Rio de Janeiro tornou-se uma verdadeira indústria, perdendo totalmente suas raízes históricas. É inegável que todos os envolvidos em sua produção são unidades de consumo e podem ser enquadrados na teoria de formação de capital simbólico a que se refere Bourdieu (1974), mas seu verdadeiro valor está na afirmação da identidade do povo carioca, tornando-se tão forte, que não é preciso tornar-se um patrimônio para garantir sua preservação ou mesmo sua divulgação.

O governo injeta dinheiro na indústria carnavalesca, mas acaba arrecadando muito mais com hotéis, restaurantes e tantas outras atividades que lucram com o dinheiro deixado pelos turistas. Percebe-se então que a política, aliada ao turismo, transformouse em simbiose bastante lucrativa que se estendeu por diversos carnavais ao longo do território brasileiro. Vale observar que o mesmo modelo aplicado no Rio de Janeiro acabou sendo implantado também na Bahia e em outros carnavais do Brasil.

A tentativa de dar ao carnaval carioca traços identitários ancestrais pode ter trazido muito lucro aos que o tornaram uma festa conhecida internacionalmente, porém pode ter comprometido sua historicidade e assim condenado o carnaval brasileiro à mera condição de atrativo turístico, procurado por pessoas de diversos países, mas distante dos quesitos que o tornariam um patrimônio nacional ou mundial. O que se presencia, atualmente, é que os dois carnavais brasileiros mais populares - Rio de Janeiro e Bahia se transformaram em indústrias de música de massa, inseridos em um contexto altamente mercantil e moderno.

\section{CONSIDERAÇÕES FINAIS}

Assim como o do Rio de Janeiro, o Carnaval de Barranquilla, na Colômbia, também cresce a cada ano, atraindo grande número de participantes e ocupando área cada vez maior. Diferente, porém, do que acontece no Rio, para sobreviver o Carnaval de Barranquilla necessita de organização e de recursos financeiros, não bastando a espontaneidade da festa. Tendo começado pequena e se tornado hoje referência no país, a festa pode perder sua essência por diversos fatores, sendo um deles o fato de se ter tornado espetáculo, porque impõe padrões modernos à cultura ancestral com mudanças nos bailes, danças tradicionais e na música. A busca da espetacularização dos grupos folclóricos pode desvirtuá-los. Esses grupos para competir em condições de igualdade com os mais modernos acabam substituindo sua forma tradicional por outras mais representativas da cultura globalizada. Há também a pressão social que qualifica como pobres e cafonas os 
grupos que mantêm intacta a tradição. A comercialização do Carnaval de Barranquilla enfrenta a imposição de cores próprias da imagem corporativa das empresas patrocinadoras dos grupos folclóricos como contrapartida do financiamento da festa, o que desconfigura a ancestralidade e o simbolismo ritual das cores particulares que cada manifestação possui, segundo a tradição transmitida oralmente por diversos séculos. Para combater o uso publicitário nesse nível seria preciso maior apoio financeiro de órgãos públicos.

Na série de fatores ameaçadores às festas na Colômbia também não podemos deixar de considerar a violência resultante do conflito armado em que vive o país e que impõe ameaça imediata ao espaço cultural. Esse fator só não é mais grave porque em muitas regiões o espaço cultural é considerado um território de paz, embora nos últimos anos os atores desses conflitos armados não tenham respeitado essa consideração como antes. Muitas famílias depositárias dessas tradições e que vivem em áreas periféricas se sentem mais expostas à violência armada e acabam abandonando suas origens e migrando para outras regiões, deixando para trás a memória e a tradição locais.

Entre os fatores que ameaçam o Carnaval de Barranquilla está a influência do mundo globalizado e a penetração de uma cultura homogeneizadora imposta pelos países do primeiro mundo. Há uma pressão para que esse espaço cultural imite outros carnavais, como o brasileiro, que conseguiram êxito ou se inseriram na indústria cultural universal, transformando-se em grandes espetáculos, o que desvirtua a essência das criações estéticas tradicionais.

Já o Carnaval de Negros e Brancos, na Colômbia, se depara com forte campanha governamental buscando atrair turistas para conhecer a festa. Uma delas, divulgada logo após a festa ter sido reconhecida como Patrimônio da Humanidade, afirmava: "Para conocer el Carnaval de Negros y Blancos hay que vivirlo".

Cumpre recordar que, segundo Bourdieu (2001), o espaço social pode ser comparado a um mercado no qual os diversos atores são investidos de interesses e estratégias em busca de capitais específicos. No caso do carnaval como fenômeno social temos o capital tradição e o empresarial. Capital tradição refere-se à legitimidade acumulada pelos atores, e o capital empresarial refere-se à legitimidade acumulada pela utilização de um modelo organizacional difundido e estabelecido, ou seja, o modelo empresarial da organização.

Quanto ao Carnaval de Oruro, ou Llamerada, na Bolívia, atualmente, encontrase ameaçado. As transformações econômicas sofridas em âmbito mundial tornaram a sobrevivência difícil em Oruro por causa do declínio das atividades mineradoras e agrícolas tradicionais, assim como pela desertificação do altiplano andino que provoca emigração em massa e pela urbanização que produziu a aculturação. Esses fatores se somam à exploração financeira da festa pelo turismo. Para evitar maior comprometimento do Carnaval de Oruro várias medidas de salvaguarda foram propostas, como uma lei de proteção da cultura nacional na Bolívia, um novo código de propriedade intelectual referente à cultura nacional e tradicional, em tentativa de preservação desse rico patrimônio cultural imaterial boliviano. 
Os carnavais de Oruro, de Barranquilla e de Negros e Brancos entraram para a Lista de obras-primas do patrimônio oral e imaterial da humanidade porque preencheram uma série de requisitos exigidos pela Unesco, entre eles o de que essas festas centenárias ajudaram a construir a memória e a identidade do povo de seus países e também, em menor escala, a identidade do povo latino-americano. Ao serem considerados Patrimônio da Humanidade pela Unesco passou-se a buscar caminhos e mecanismos que garantam sua permanência e de toda a tradição neles contida sem que a globalização as desfigure, pela consequente adaptação à lógica do mercado globalizado, evitando a transformação dessas festas populares em meros produtos culturais por um lado e, por outro, assegurando a manutenção da tradição com o caráter identitário, com o mínimo de deturpação ou destruição de sua essência e respeitando-se a dinâmica da cultura, que jamais será imutável. Nesse caso, inseri-las na Lista de obras-primas do patrimônio oral e imaterial da humanidade é forma de ajudar sua salvaguarda e preservação.

Não se deve considerar todo o carnaval brasileiro uma farsa, mas pensar que o carnaval carioca, assim como o baiano, já estão instituídos e se mantêm independente de registros. Além do que o samba-enredo é considerado patrimônio imaterial e o samba de roda do Recôncavo Baiano também foi recentemente registrado como patrimônio imaterial pelo Iphan. Igualmente, não se pode ignorar o grande filão de mercado que as festas brasileiras têm alcançado e, ao contrário de Bolívia e Colômbia, o Brasil em alguns casos parece agir em conivência com os setores que geram lucro. Percebe-se, de forma mais nítida, a criação de uma "identidade-para-o-mercado" e o "pastiche da historicidade" (MACHADO, 2004, p. 208).

Não se pode esquecer que as festas populares são fundamentais para a preservação da memória e da identidade de uma comunidade ou nação, logo precisam de salvaguarda. Também não se deve engessar essa riqueza cultural como um passado imutável. A festa tem justamente o papel de reavivar esse passado na forma de presente para evitar um futuro sem memória. Ela deve estar atualizada sem perder suas raízes. Ela pode gerar lucro e movimentar a economia local, mas para isso é preciso que esteja protegida em sua essência para que não se desvirtue.

\section{REFERÊNCIAS BIBLIOGRÁFICAS}

BOURDIEU, Pierre. O mercado dos bens simbólicos. In MICELLI, Sérgio (org.). A economia das trocas simbólicas. São Paulo: Perspectiva, 1974, p. 99-181.

. A identidade e a representação: elementos para uma reflexão crítica sobre a idéia de região. In O poder simbólico. Tradução Fernando Tomaz. 4. ed. Rio de Janeiro: Bertrand Brasil, 2001, p. 107-132.

ELIADE, Mircea. O sagrado e o profano. São Paulo: Martins Fontes, 2002.

FERREIRA, Felipe. O livro de ouro do carnaval brasileiro. Rio de Janeiro: Ediouro, 2004.

FERREIRA, Maria Nazareth. As festas populares na expansão do turismo. São Paulo: Arte \&Ciência, 2001.

HOBSBAWM, Eric. A invenção das tradições. Rio de Janeiro: Paz e Terra, 1997. 
MACHADO, Igor José de Reno. Estado-nação, identidade para o mercado e representações de nação. Revista de Antropologia, v.47, n.1. São Paulo, 2004, p. 208-234.

MUKUNA, Kazadi wa. Contribuição bantu na música popular brasileira: perspectivas etnomusicológicas. São Paulo: Terceira Margem/Cesa, 2006.

ORTIZ, Renato. Estado autoritário e cultura. In ORTIZ, R. Cultura brasileira e identidade nacional. 5.ed. São Paulo: Brasiliense, 1994.

NOGUEIRA. Rodrigo Muniz. O carnaval como uma peça da construção identitária brasileira. Caderno Virtual de Turismo, v.8, n.1, Universidade Federal do Rio de Janeiro, 2008. Disponível em: www.ivt.coppe.ufrj.br/caderno/ojs/viewarticle. php?id=275\&layout=abstract. Acesso em: 29 jul 2010.

QUEIROZ. Maria Isaura Pereira. Carnaval brasileiro: o vivido e o mito. São Paulo: Brasiliense, 2005.

SINNING, Edgar Rey. El carnaval de Santa Marta, la fiesta de todos: los primeros treinta años del siglo XX. Textos Escolhidos de Cultura e Arte Populares. Rio de Janeiro, v.6, n.1, 2009, p.31-50.

UNESCO. Lista de obras-primas do patrimônio oral e imaterial da humanidade. Disponível em: www.unesco.org. Acesso em agosto de 2010.

Edson Leite é livre-docente da Escola de Artes, Ciências e Humanidades e do Programa de Pós-Graduação Interunidades em Estética e História da Arte da Universidade de São Paulo.

Maria Cristina Caponero é mestre em ciências da comunicação pela Escola de Comunicações e Artes, mestre em estética e história da arte pelo Programa de Pós-Graduação Interunidades da Universidade de São Paulo e doutoranda em história da arquitetura e do urbanismo pela Faculdade de Arquitetura e Urbanismo da Universidade de São Paulo. Simone Perez é jornalista e mestranda em estética e história da arte pelo Programa de Pós-Graduação Interunidades em Estética e História da Arte da Universidade de São Paulo.

Artigo recebido em agosto de 2010 e aceito para publicação em outubro 2010. 